\title{
A Descriptive Analysis of the Temporal and Geographical Proximities Seen Within UK Series of Sex Offenses
}

\author{
Jessica Woodhams ${ }^{1}$ (D) $\cdot$ Kari Davies ${ }^{1} \cdot$ Sarah Galambos $^{2} \cdot$ Mark Webb $^{2}$
}

Accepted: 9 August 2021 / Published online: 21 August 2021

(c) The Author(s) 2021

\begin{abstract}
Previous studies of the geographical and temporal features of serial sex offenses are limited by small samples and/or geographical areas, and are dated. We address a significant gap in the literature by investigating the temporal and geographical proximity of the crimes of 402 serial stranger sex offenders in the UK. Periods of incarceration were extracted from calculations of temporal proximity giving a more accurate picture of series duration and time elapsed between offenses from the same series. A notable minority of serial stranger sex offenders commit their offenses within very close geographic proximity and the same was found for temporal proximity. There were also occurrences of series spanning large distances and many years. The implications of these findings for the use of geography and time in the behavioral linking of crimes, and what they mean for policy decisions regarding financial investment in law enforcement technology, are discussed.
\end{abstract}

Keywords Inter-crime distance $\cdot$ Geographic proximity $\cdot$ Temporal proximity $\cdot$ Serial rape $\cdot$ Serial sex offences

\section{Introduction}

While there has been significant scholarly work on serial offenders' journeys to crime (i.e., from their home residence or another significant anchor point), there is little empirical research on the spatial and temporal distances between the crime scene locations themselves. Empirical knowledge of the inter-crime distances of offenders in terms of time and geographical space are relevant to topics such as "the Near Repeat phenomena" and the behavioral linking of crimes (i.e., "crime linkage"; see Tonkin 2014, for a summary). This paper summarizes the findings from historic papers regarding the temporal and geographical distances between offenses from the same series and considers what this means for crime linkage and the Near Repeat phenomena. In addition, it reports a new empirical study of the temporal and geographical proximities of offending observed within the largest sample of United Kingdom (UK) serial sex offenders studied to date.

Jessica Woodhams

J.Woodhams@bham.ac.uk

1 School of Psychology, University of Birmingham, Edgbaston, Birmingham B15 2TT, UK

2 Serious Crime Analysis Section, National Crime Agency, London, UK
The range of crime scene behavior displayed by offenders can be broad and can include target selection behaviors, control behaviors, escape or planning behaviors, property stolen, sexual behaviors, and, of course, geographical and temporal behavior (Grubin et al. 2001; Rebocho and Silva 2014). Several criminological and psychological theories exist that attempt to explain the geographical behavior and temporal patterns of criminals' behavior (Beauregard et al. 2005; Rossmo 2000). These include mental maps (Canter and Gregory 1994), routine activity theory (Cohen and Felson 1979), bounded rational choice theory (Cornish and Clarke 1986), and crime pattern theory (Brantingham and Brantingham 2011). Evidence of the relevance of these theories for offender decision making can be seen in case studies of serial sex offenders (e.g., Strangeland 2005), and their implication that offenses by serial sex offenders will be clustered in space and time has some support from the empirical literature on the Near Repeat phenomenon, crime linkage, the journey-to-crime literature, and studies of the environmental range of serial rapists (Canter and Larkin 1993; Grubin et al. 2001; Youstin et al. 2011).

The Near Repeat phenomenon "suggests that when a crime occurs in a given area, the surrounding area may exhibit an increased risk for subsequent crime in the days following the original incident" (Youstin et al. 2011, p. 1042). Questions have been raised as to whether the nearrepeat phenomenon is a result of the targeting of multiple victims/occupancies in close proximity to one another by 
a serial offender over a short time period (e.g., Youstin et al. 2011). Due to data collection methods, often this has been difficult to determine with confidence (i.e., there has been no data available on individual offenders). However, a study by Bernasco (2008) of burglaries occurring in the Hague, in the Netherlands, demonstrated that most nearrepeat phenomena could be explained by the actions of a serial burglar who had committed the original offense and also the "near-repeats." A study by Johnson (2013) of UK serial burglars concluded that most commit spatially and temporally clustered series, with exceptions who travelled tens of kilometers. No equivalent studies with sex offenses could be found and research into the generalizability of the Near Repeat phenomenon has found variation in geotemporal patterns between crime types (although, again, without data on individual offenders). Such variation is likely indicative of differences in the underlying motivation for offending (Youstin et al. 2011). For sex offenses, geo-temporal patterns are also likely to be affected by the availability of suitable victims (the target backcloth; Rossmo 2000). It is not, therefore, appropriate to generalize from studies of the near-repeat phenomenon with nonsexual crime and assume that the offenses of serial sex offenders will also be spatially and temporally clustered.

In 2005, Beauregard et al. reviewed the empirical research published between 1965 and 2000 for sex offenders' journey-to-crime (rather than distance between crime sites). These studies included some with homicide offenders and the review was not limited to serial sex offenders (only 8 of the 20 studies were of serial offenders). The distances travelled from home to offense varied from 0 miles to more than 100 miles (or $161 \mathrm{~km}$ ). An even larger range of 0 to $485 \mathrm{~km}$ (301 miles), with a median of $3 \mathrm{~km}$ (1.9 miles), was reported for 76 New Zealand serial sex offenders by Lundrigan et al. (2010). Slightly smaller median values were reported by Rossmo et al. (2004) for 373 UK stranger rapes - the median distance from offender residence to the encounter site was $2.4 \mathrm{~km}$, to the offense location was $1.7 \mathrm{~km}$, and to the release location was $1.8 \mathrm{~km}$. While this research is key to investigative practices such as geographic profiling, it does not assist with understanding the distances between offenses from the same series since some serial rapists will travel great distances from their home location to commit their crimes (referred to by Canter and Larkin (1993) as a "commuter") yet their offenses might still be clustered within a specific geographical area (and thus have small inter-crime distances).

Within the literature on crime linkage, it has been found repeatedly for volume crime that crime pairs in close geographical and temporal proximity are much more likely to have been committed by the same offender versus two different offenders (Tonkin 2014). With regard to serial sex offenses specifically, few studies have examined the value of inter-crime distance or temporal proximity for linking crimes. Of those that have, Yokota et al. (2017) demonstrated that inter-crime distance improved overall linkage prediction accuracy when combined with other behavioral information (i.e., modus operandi behaviors). Grubin et al. (2001) also found that including information about the temporal proximity and inter-crime distance of offenses increased the linkage "hit" rate (correctly identifying links between crimes by the same offender); however, it also increased the "miss" rate (missing links between crimes by the same offender), suggesting that not all serial sex offenders commit their crimes close together in time and space. Woodhams (2008) also investigated the utility of inter-crime distance with regard to linking serial sex offenses committed by juveniles, finding that intercrime distance was able to very accurately predict whether crime pairs were committed by the same (linked) versus two different offenders (unlinked). However, these findings need to be interpreted with caution given the relatively small sample sizes spread over large geographic areas (certainly for the Woodhams and Grubin et al. studies; Bennell and Canter 2002; Woodhams 2008).

Descriptive statistics reported in studies of crime linkage give some insight into the temporal proximities of serial sex offending. For Santtila et al.'s (2005) sample of 43 Finnish serial sex offenders, the overall median series duration from first to last offense across the whole sample was 8 months; however, the average time between rapes from the same series ranged from 11 days to 8 years. Similarly wide parameters were seen in Winter et al. (2013)'s sample of 90 UK serial rapists; the median temporal distance between first and last offense in the series was 373 days, and the shortest duration between two offenses in a given series ranged from 1 day to 13.7 years. The average series length found for a Canadian sample of 72 serial sex offenders was 1718 days (5 years; Deslauriers-Varin and Beauregard 2014).

In 1993, Canter and Larkin conducted a study of the distances travelled by 45 serial stranger sex offenders in England. This included information about the maximum distances travelled between each offenders' furthest apart offenses. These distances ranged from 0 to 46 miles $(74 \mathrm{~km})$. The offenders had been convicted of between two and 14 offenses each with a mean of 5.6 offenses. All offenses were specific to a geographical region of England - Greater London and the South East of England - and all offenses dated from the 1980s. In 2004, Rossmo et al. calculated the median nearest-neighbor distances and the median mean k-order nearest-neighbor distance for $17 \mathrm{UK}$ series of stranger rape. The distances were $1.0 \mathrm{~km}$ and $2.0 \mathrm{~km}$, respectively. Both studies are now considerably dated and it is likely that people's travel patterns (including those of offenders) have changed. For example, the number of cars licensed each year continues to increase (Department for Transport 2019), and the use of public transport has changed over time (Department for Transport 2018). 
Current and robust research findings regarding the temporal and geographical proximities of sex offending are important for academia, and they are also of significance to policing practice in several countries. For example, when conducting crime linkage in the UK and Belgium, studies of analysts' decision-making have shown that analysts conduct geographybased searches of the Violent Crime Linkage Analysis System (ViCLAS) using average inter-crime distances for serial sex offenders (Davies et al. 2018; Davies and Woodhams 2020). When constructing their searches, they also consider time in terms of considering historic equivalents for more modern offending behaviors; for example, crime analysts will generate hypotheses regarding the sort of approach style an offender might have used pre-Internet if series are believed to span such time periods (Davies et al. 2018).

Furthermore, the premise for establishing national crime linkage units in many countries of the world (e.g., Canada, the Netherlands, Belgium, Switzerland, Ireland, Austria, and the UK) was because of infamous cases of serial rapists and murderers who had travelled large distances when committing their crimes and, because of this, evaded capture for some time. These units were established to avoid linkage blindness (Egger 1984), which is where series are missed and therefore not "linked" due to offenders crossing jurisdictional boundaries. Their existence is partially based on the belief that some serial sex offenders travel large distances to offend and/or cross police jurisdictional boundaries. In addition, in the UK, the existence of 45 different police forces ${ }^{1}$ means that offenders can commit offenses that cross police jurisdictional boundaries with relative ease. This issue may be further exacerbated in countries like the USA, where different states are even more jurisdictionally separate, with some following different penal codes. Evidence that serial offenders are travelling large distances or are crossing jurisdictional boundaries to offend provide evidence for initiatives in policy and practice that encourage and facilitate the sharing of data and intelligence between police forces in a timely manner (e.g., establishment of the National ANPR System [the NAS]; Home Office 2019).

Academic research about the geographical and temporal patterns of serial sex offending can, therefore, provide important insights regarding approximate timespans and geographical areas over which serial sex offenders operate which can support or conflict with theories regarding the geo-temporal nature of offending. For example, evidence of the temporal and geographical clustering of serial stranger sex offending would suggest some explanatory value for the role of serial offending in the Near Repeat phenomenon.

\footnotetext{
1 The policing of the UK is the responsibility of 45 territorial police forces (including the Police Service of Northern Ireland and Police Scotland). For a map of the police force areas, see https://www.justiceinspectorates.gov. uk/hmicfrs/media/police-force-map.pdf
}

These insights are also relevant to the existence of national crime linkage units, analyst decision-making and search strategies for interrogating databases such as ViCLAS, and government initiatives to facilitate information sharing across police jurisdictional boundaries that could enhance the detection and apprehension of sex offenders (e.g., creation in the UK of the National Automatic Number Plate Recognition [ANPR] Service).

Despite this need, there are few studies of the inter-crime distances (both temporal and geographical) between sex offenses of the same series, and limited knowledge of the time spanned by entire series. Those studies that do exist have small samples, are limited to specific geographical areas, and therefore do not provide a national picture, and/or are dated. In addition, from what we could determine, no previous study has considered how periods of incarceration might affect the apparent length of time over which sex offense series occur.

For example, in the UK, the typical sentence for someone convicted of a sexual offense is just less than 5 years (excluding life and indeterminate sentences; Ministry of Justice 2020) and offenders can serve half of this time in prison. Periods of incarceration could therefore alter the apparent duration of a series and the temporal distances between offenses from the same series by several years if not taken into account. The Serious Crime Analysis Section (SCAS) holds the largest dataset of information about convicted serial sex offenders and their offenses in the UK. Using their data, we were able to address these significant limitations by sampling the largest and most current group of convicted serial sex offenders to date, spanning 20 years.

Our research questions were:

1. Over what period of time do serial sex offenders commit their offenses?

2. How far apart in time and space are the offenses of serial sex offenders?

3. How do (1) and (2) change when accounting for periods of incarceration?

\section{Method}

\section{Data}

The study is based on the offending behavior of 469 convicted male serial stranger sex offenders, the details of which were obtained from SCAS in the UK. As the unit with national responsibility for analyzing sex offending behavior, SCAS collates the most comprehensive collection of police files on cases of stranger sexual assault in the UK. The 469 offenders represented all convicted serial sex offenders on their system at the time of data collection. "Serial" was defined as a perpetrator who had committed two or more sex 
Table 1 The lengths of series as measured by the number of crimes per series $(N=469)$

\begin{tabular}{llllllllllllllllllll}
\hline No. of offenses in series & 2 & 3 & 4 & 5 & 6 & 7 & 8 & 9 & 10 & 11 & 12 & 13 & 14 & 15 & 16 & 17 & 18 & 19 & 20 \\
No. of series of each length & 281 & 87 & 41 & 23 & 10 & 8 & 6 & 7 & 3 & 0 & 0 & 1 & 1 & 0 & 0 & 0 & 0 & 0 & 1 \\
\hline
\end{tabular}

offenses (for which they were convicted) against different victims and reflects the common definition adopted in the academic literature and by international police forces (e.g., Federal Bureau of Investigation 2008; Grubin et al. 2001; Santtila et al. 2005). Most series $(60 \%, n=281)$ within the dataset consisted of two offenses with the number of series decreasing as series length increased (see Table 1).

\section{Procedure}

The study was scrutinized and approved by the University of Birmingham's Science, Technology, Engineering and Mathematics Ethics Committee (ERN_16-0737). An information sharing agreement between the University of Birmingham and the police partners governed data management and data security.

To ensure individual offenses (and therefore victims/perpetrators) could not be identified by the researchers, SCAS calculated the inter-crime distance between each pair of crimes in each series and provided these to the researchers in an Excel spreadsheet, rather than giving the researchers the locations to plot themselves. These calculations were based on the geographical coordinates of each site in each offense. A stranger sex offense involves at least three sites: an initial contact site, an offense site, and a victim release/ disposal site. These three sites can all be at the same location (i.e., the victim and offender do not move location during the offense), or an offense can involve two or more different locations. Rather than make any assumptions about which site(s) was of greater importance to the offender, the statistical analyses were based on the site for each offense that resulted in the largest geographical distance between two offenses (e.g., the initial contact location for offense 1 in series 1 and the victim release/disposal location for offense 2 in series 1 were the most geographically disparate and were therefore chosen). Inter-crime distances were all calculated based on the Euclidean distance (Rossmo et al. 2004) as has been the case in previous studies of serial offenders (Markson et al. 2010; Tonkin et al. 2011). In addition, for each crime series, the police force $(s)^{2}$ in which the offenses occurred was provided to the researchers.

The start date for each offense was provided to the researchers by SCAS. Where the time period for a given offense spanned across more than 1 day $(n=198)$, the earliest date was used in calculating the number of days between a pair of

\footnotetext{
$\overline{2}$ The sample included offenses from the 45 territorial police forces, as well as offenses from the MoD police and the Transport Police.
}

offenses within the same series/first and last known offense. Every offender had been convicted of at least two stranger sexual offenses (including rape, sexual assault, indecent exposure, abduction, attempted abduction, attempted murder or murder). All offenses in their series were, however, defined by SCAS as sexual offenses (e.g., murders and abductions had a sexual element). ${ }^{3}$

The personal details of each perpetrator were given to the second author to extract information from the Police National Computer (PNC) and the Prisoner Intelligence Notification System (PINS), to see if, and for how long, each perpetrator had been incarcerated during the time period between their first and last known offense. This was to ensure that any periods of incarceration were subtracted from the calculations of the time elapsed between the start and end of each series, and between offenses from the same series. Periods of incarceration were not necessarily for sex offending. The second author is trained in the use of each of these systems and both the first and second authors had a sufficient level of police vetting to view such data. This data extraction took place on a secure police site and data were anonymized before being removed off-site. For 117 of the 469 offenders, data implied they were incarcerated at some point but the incarceration data were either missing or incomplete (such as the presence of a conviction and sentence on an offender's record on PNC, but no incarceration data length on PINS); therefore, they were excluded from the analysis of temporal patterns. Consequently, the total sample of offenders for the temporal analysis was 352 . Of the 352 offenders, 17 had complete incarceration data and the remaining 335 had no history of incarceration during the time period of their sex offense series analyzed here.

For 66 of the 469 serial sex offenders, geolocation data were missing for the offenders' crimes; therefore, the total sample of offenders for the geographical proximity analysis was 403. All distance calculations used kilometers as the unit of measurement. For 144 of these offenders, it was known that the perpetrator had used a vehicle in at least one of their crimes in the series (as reported by the victim).

\footnotetext{
${ }^{3}$ Given findings in the literature regarding the versatility of serial rapists (e.g., Lovell et al. 2017) and that their series can contain offenses from different legal categories (i.e., abduction and rape, or rape and indecent assault), we did not limit our sampling of the individuals' offending to only one type of sexual offense, nor did we wish to limit our analyses to homogenous series only, for reasons of ecological validity.
} 
Table 2 Descriptive statistics for the total and average offending periods across offenders (average of each offender's average)

\begin{tabular}{lccccr}
\hline Time period in days & $\begin{array}{l}\text { Total offending } \\
\text { period }\end{array}$ & $\begin{array}{l}\text { Incarceration } \\
\text { periods }\end{array}$ & $\begin{array}{l}\text { Total offending period } \\
\text { minus incarceration }\end{array}$ & $\begin{array}{l}\text { Average time period } \\
\text { between offenses }\end{array}$ & $\begin{array}{l}\text { Average time period between } \\
\text { offenses minus incarceration }\end{array}$ \\
\hline Mean & 510.15 & 56.57 & 453.59 & 312.97 & 274.75 \\
Median & 68.00 & 0.00 & 68.00 & 38.00 & 38.00 \\
Minimum & 0.00 & 0.00 & 0.00 & 0.00 & 0.00 \\
Maximum & 7062.00 & 3948.00 & 7062.00 & 7062.00 & 7062.00 \\
\hline
\end{tabular}

Crucially, however, analyses were not limited to these 144 offenders, since it has been documented that serial offenders may travel to the locality of the approach location but approach the victim on foot, meaning that the victim would not observe, and consequently report, the vehicle that had been used by the perpetrator (e.g., Strangeland 2005).

\section{Results}

\section{Temporal Proximity}

The timespan covered by each series was calculated in number of days. From this number, the period(s) of incarceration in number of days was subtracted to give a more accurate figure of the number of days over which a series occurred. In addition, the time elapsed between offenses in the same series (calculated using all possible crime pairs) was computed with and without incarceration periods subtracted. This information is displayed in Table 2.

The time period between a crime pair from the same series was also determined for each consecutive pair. This can be calculated taking the most recent crime as the starting point (see Table 3 where the various measures of central tendency are recorded), or the most historic crime (i.e., the first known offense in a series) as the starting point. ${ }^{4}$ Reporting rates for sex offenses have increased since the 1970s and more recently (Office for National Statistics 2017), which could give the illusion that offenses are occurring closer together in time. In addition, improvements in forensic techniques may have facilitated the linking of more offenses in recent years, again giving the illusion that crimes are occurring closer together in time within known series. For these two reasons, we think it is prudent to place greater weight on our findings where the most recent crime has been utilized as the starting point.

Histograms ${ }^{5}$ were also produced for the full distributions of series duration and days between offenses from the same series. These reveal skewed distributions, where more than

\footnotetext{
$\overline{4}$ Tables with this latter data within are available online as supplementary materials.

5 The histograms are available online as supplementary materials.
}

$65 \%$ of entire series span less than 6 months and just less than $67 \%$ of same-series crime pairs were 6 months or less apart (see Table 4).

\section{Geospatial Proximity}

The geographical data for each series was used to calculate an average (mean) distance between offenses in the same series and an average distance overall (encompassing all 403 offenders). The average distance between offenses from the same series ranged from 0.00 to $641.50 \mathrm{~km}(0.00$ - 398.61 miles). The overall average inter-crime distance for the whole sample (the mean of the averages) was $21.40 \mathrm{~km}$ (13.30 miles). See Table 5 for further descriptive statistics.

The geographical data for the series were also used to determine the furthest distance travelled within a series for each offender. The descriptive statistics for these analyses can also be seen in Table $5 .^{6}$

In addition, the percentages of series whose two most geographically disparate crimes fell within various cutoffs for maximum distance were calculated. For $30.27 \%$ of offenders within the sample, their two most distant crimes in their series were $1 \mathrm{~km}$ or less apart, for $47.39 \%$ of offenders they were $2 \mathrm{~km}$ or less apart, for $54.84 \%$ they were $3 \mathrm{~km}$ or less apart, for $59.31 \%$ they were $4 \mathrm{~km}$ or less apart, for $62.28 \%$ they were $5 \mathrm{~km}$ or less apart, and for $69.98 \%$ of offenders they were $10 \mathrm{~km}$ or less apart.

For 14 series, there was $0 \mathrm{~km}$ between two or more of the offenses within the series. On examination of these 14 series, for only three was the offense location for two or more crimes in the series the suspect's home location. For the remainder, the suspect was returning to the same location to either approach or assault different victims. These locations varied in type - some were outdoor locations and others were indoor locations.

Seventeen $(4.22 \%)$ of the offenders in the sample had offenses more than $161 \mathrm{~km}$ (100 miles) apart. Within these 17 offenders, there appeared to be offenders who were very mobile, travelling large distances within the same time period, as well as offenders who had two or more distinct

\footnotetext{
${ }^{6}$ A histogram of the distribution is available in the online supplementary materials.
} 
Table 4 The number (and percentage) of crime pairs from the same series $(n=702)$, or entire series $(n=352)$ falling within specific time spans

\begin{tabular}{llllll}
\hline & $\begin{array}{l}2 \text { months } \\
\text { (60 days) }\end{array}$ & $\begin{array}{l}\text { 6 months } \\
(180 \text { days })\end{array}$ & 1 year & 2 years & 3 years \\
\hline Crime pairs & 322.00 & 468.00 & 526.00 & 585.00 & 610.00 \\
& $(45.89)$ & $(66.67)$ & $(74.93)$ & $(83.33)$ & $(86.89)$ \\
Series & 163.00 & 228.00 & 254.00 & 286.00 & 294.00 \\
& $(46.31)$ & $(64.77)$ & $(72.16)$ & $(81.25)$ & $(83.52)$ \\
\hline
\end{tabular}

clusters of offenses. To provide further information about these 17 offenders, we examined the location of their residence at the time of the offenses. Twelve of the offenders either travelled into a different county from their place of residence at the time of the offense, or they travelled within the same county as their address but their journey would have taken more than $90 \mathrm{~min}$ by car from residence to the offense location. The remaining five offenders had two or more distinct locations for their offending which were close to their residence at the time (hence they had offenses far apart in space but which were close to one of their residences).

The data about the police force area in which each offense occurred were used to determine whether the serial offenders were travelling across multiple police force jurisdictions. Analyses showed that $15.38 \%(n=62)$ of the serial offenders crossed police jurisdictional boundaries during their series. Fifty-five $(88.71 \%)$ of these offenders committed offenses in two different police jurisdictions, three offenders $(4.84 \%)$ in three different jurisdictions, three $(4.84 \%)$ in four different jurisdictions, and one offender $(1.61 \%)$ who offended in five different police jurisdictions. Of these 62 series, $29(46.77 \%)$ took place in police force jurisdictions that were not neighboring (i.e., they did not share geographical borders).

\section{Discussion}

This paper set out to update empirical findings regarding the periods of time and space over which serial sex offenders commit their offenses. The overall length of time spanned by 352 individual series was calculated as were the numbers of days between offenses in the same 352 series. The

Table 5 The average distances (and range) and the furthest distances (and range) in $\mathrm{km}$ travelled by offenders in their series $(n=403)$

\begin{tabular}{lrr}
\hline & Average & Furthest \\
\hline Mean & 21.40 & 27.20 \\
Median & 1.88 & 2.39 \\
Minimum & 0.00 & 0.00 \\
Maximum & 641.50 & 641.50 \\
\hline
\end{tabular}


Euclidean distance between each pair of crimes from each series was calculated for 403 series allowing us to determine the furthest distance between crimes from the same series. An advantage of our study was the large number of offenders on which we had data, representing the largest sample of serial sex offenders in the UK analyzed to date.

Approximately one-third of offenders left no further than $1 \mathrm{~km}$ between crimes in their series and approximately half the sample no more than $2 \mathrm{~km}$. According to crime pattern theory (Brantingham and Brantingham 2011) and routine activity theory (Cohen and Felson 1979), this clustering of crime locations within a sexual offense series would be explained by the different offenses occurring close to an offender's activity node (e.g., home, place of employment), a place where the offender encounters a suitable victim while engaged in their routine activity. Another explanation is that the offender travels to the location because of the target backcloth (Rossmo 2000), i.e., it is at this location where desired victims are to be found. Some victim types will be more clustered spatially (e.g., sex workers, schoolchildren, and students living on campuses; e.g., Beauregard et al. 2007; Breetzke et al. 2021) and so crimes against these victims would result in spatial clustering in the series. In this scenario, it is the victims' activity nodes that are creating a clustering in space.

Just under $70 \%$ of the offenders left no more than $10 \mathrm{~km}$ between offenses in their series. The vast majority of Canter and Larkin's (1993) sample also travelled less than $10 \mathrm{~km}$ between their furthest two offenses. Exact statistical figures are not available in Canter and Larkin (1993); however, from the graphs included in their paper this can be determined visually. These findings are similar despite one study having a regional focus and the other having a national focus. However, differences are apparent when you compare the minimum and maximum figures for the two most distant offenses from each series (i.e., 0 vs. 46 miles compared to 0 vs. 399 miles here). ${ }^{7}$

The duration of series ranged from all offenses occurring within the same 24 hours to 7062 days (just over 19 years). The median was 68 days. The median time between offenses from the same series was 38 days but ranged from 0 to 7062 days (just over 19 years). What was novel about our study was the subtraction of any periods of incarceration from these figures to ensure we were accurately portraying time "at large." Our range of average temporal distances between two offenses from the same series was comparable to that of Santtila et al. (2005) and Winter et al. (2013); however, our median was much smaller than these two studies (two months compared to 8 months and 12 months, respectively)

\footnotetext{
${ }^{7}$ Comparisons are not made with Rossmo et al. (2004) here since they removed from their analyses offenses that were greater than $100 \mathrm{~km}$ apart.
}

as well as compared to Deslauriers-Varin and Beauregard (2014; 5 years). It is apparent that this difference in findings is not entirely due to the subtraction of incarceration periods and instead might reflect a broader, and therefore perhaps more diverse, sample in the present study (i.e., a broader range of sexual offenses).

That a notable majority of offenders' crimes were within close proximity suggests that geography and time might be useful factors for linking sexual crime, similar to what has been found for volume crime. Existing studies of serial sex offenses that have investigated the use of geographical proximity for linking are problematic because of their relatively small, but nationally spread, samples (e.g., Grubin et al. 2001; Woodhams 2008). Therefore, this is an empirical question that warrants testing on a large dataset that includes not just the offenses of convicted serial sex offenders (i.e., that includes unsolved and apparent one-off crimes). Ecological validity could be further enhanced by including details of unsolved but linked-by-DNA series (i.e., series that have been linked by scene-to-scene forensic matches but for which the offender has never been identified nor apprehended). Such a dataset would also allow for a test of the Near Repeat phenomena with stranger sex offenses.

\section{Practical Implications}

The premise for national units responsible for crime linkage and the analysis of sexual offenses is that some serial sex offenders have a large environmental range and they cross police jurisdictional boundaries. Our research shows this premise to be correct for a small minority of apprehended offenders; 17 of 403 offenders in our dataset had two crimes more than 100 miles $(161 \mathrm{~km})$ apart. It also showed that approximately one-sixth of offenders on SCAS's ViCLAS database committed sex offense series that crossed police jurisdictional boundaries. Some of these individuals were offending in non-neighboring police jurisdictions. It is important to remember that our analysis is based on only convicted serial sex offenders; without research on the distance travelled by undetected serial rapists, it is difficult to know how many of these travel large distances but it would seem reasonable to hypothesize that undetected rapists may be harder to detect because they travel further and/or crossjurisdictional boundaries - therefore, the percentage who cross boundaries might be higher in the undetected series.

Our paper therefore lends support to the argument that units are needed that take a national view of sexual offending. Our findings also lend support to government efforts to provide technological solutions (e.g., the NAS) to law enforcement that provide a national data picture (rather than being limited to within-force data) and the importance of easy access to such data in detecting offenders who travel to offend. 
It has been recorded in research of crime analyst decisionmaking (Davies et al. 2018; Davies and Woodhams 2020) that a key part of the crime linkage process is to conduct geography-based searches of databases such as ViCLAS, which are used internationally to support crime linkage. The new findings presented here are therefore relevant to crime analysts conducting crime linkage on sex offenses in the UK and indicate the sort of empirical research that needs to be conducted (and regularly updated) to inform these sorts of searches in other countries. It cannot be assumed that the travel patterns of or distances covered by UK serial sex offenders will be equivalent to those in other countries, which is why such research needs to be country-specific (e.g., see Lundrigan and Czarnomski 2006; Sarangi and Youngs 2006).

\section{Limitations}

Due to the nature of statistical analyses on which our findings must be based, we required a sample where we could be confident that offenses were attributed to the responsible offender. We therefore needed to sample convicted serial sex offenders. In 2002, Bennell and Canter argued that solved serial burglaries would be expected to be characterized by greater levels of behavioral consistency and distinctiveness than unsolved serial burglaries, as these characteristics likely contributed to their detection as a series. A logical extension of their argument would be that solved crime series would be expected to be more temporally and geographically clustered than unsolved crime series again because this likely aided in their detection as a series. Research comparing apprehended versus unapprehended sex offenders has shown that there can be differences between their offense behaviors (Lovell et al. 2017); however, Lammers (2013) reported no differences for arrested versus non-arrested serial offenders in the mean inter-crime distance between their offenses.

It should also be noted that the offenses within our sample are those that victims chose to report to the police in the first place and which were subsequently prosecuted and for which the offender was convicted. Research on victim demographics, personal circumstances, belief in the police, and their relationships with reporting behavior have all been conducted with many findings being mixed and inconclusive (see Boateng 2018, for a recent summary). How these factors might impact on the diversity of our sample is unclear; however, it should at least be noted that our sample will be a select one and will not be representative of all serial sex offenses committed in the UK. Our data will also not be a complete record of the offenders' sexual offending histories bearing in mind the low conviction rate for rape in England and Wales (Hohl and Stanko 2015). Our focus on serial stranger sex offending will mitigate this to some extent given that offenses committed by offenders who are strangers to their victims are more often reported to police and more likely to lead to a conviction (Waterhouse et al. 2016).

Previous research on journey-to-crime distances has noted associations between journey length and the perpetrator having previous convictions (Warren et al. 1998), perpetrator demographic characteristics (e.g., age; Davies and Dale 1996), offense characteristics (e.g., approach style; LeBeau 1987), and the local topography (Canter and Larkin 1993). It was not possible to investigate whether such associations could also be found with inter-crime distance due to information on the offenders, local topography, and modus operandi not being part of the data provided to us. This would be an interesting avenue for future research.

In conclusion, our paper has filled a gap in the empirical literature regarding the geographical and temporal distances between crimes from the same sexual offense series. The last studies on the distances travelled between offenses by UK serial rapists were published in 1993 and 2004, and were limited to 45 and 17 offenders/series, respectively. Previous studies reporting the temporal proximities of offenses from the same sex offense series are also limited by small sample sizes. This paper updates and extends this previous work to a sample of more than 400 convicted offenders and overcomes key limitations. It has implications for police efforts to identify sexual offense series and detect the offenders responsible for them.

Supplementary Information The online version contains supplementary material available at https://doi.org/10.1007/s11896-021-09473-8.

Acknowledgements We would like to thank Ben Costello for assisting in formatting an earlier version of this manuscript and Barbara Vinagre Mota for assisting with the data analysis regarding the "long-distance" offenders.

Funding The research was funded from the University of Birmingham's ESRC IAA block grant (RRAI19386) and by the National Police Chief's Council.

Data Availability The datasets analyzed during the current study are not publicly available as the data are owned by the National Crime Agency.

\section{Declarations}

Conflict of Interest The authors declare no competing interests.

Ethics Approval This article does not contain any studies with human participants or animals performed by any of the authors.

Informed Consent Not applicable.

Open Access This article is licensed under a Creative Commons Attribution 4.0 International License, which permits use, sharing, adaptation, distribution and reproduction in any medium or format, as long as you give appropriate credit to the original author(s) and the source, provide a link to the Creative Commons licence, and indicate if changes were made. The images or other third party material in this article are included in the article's Creative Commons licence, unless indicated 
otherwise in a credit line to the material. If material is not included in the article's Creative Commons licence and your intended use is not permitted by statutory regulation or exceeds the permitted use, you will need to obtain permission directly from the copyright holder. To view a copy of this licence, visit http://creativecommons.org/licenses/by/4.0/.

\section{References}

Beauregard E, Proulx J, Rossmo DK (2005) Spatial patterns of sex offenders: theoretical, empirical and practical issues. Aggress Violent Beh 10:579-603. https://doi.org/10.1016/j.avb.2004.12.003

Beauregard E, Rossmo DK, Proulx J (2007) A descriptive model of the hunting process of serial sex offenders: a rationale choice perspective. J Fam Violence 22:449-463. https://doi.org/10.1007/ s10896-007-9101-3

Bennell C, Canter DV (2002) Linking commercial burglaries by modus operandi: tests using regression and ROC analysis. Sci Justice 42:153-164. https://doi.org/10.1016/S1355-0306(02)71820-0

Bernasco W (2008) Them again? Same-offender involvement in repeat and near repeat burglaries. Eur J Criminol 5:411-431. https://doi. org/10.1177/1477370808095124

Boateng FD (2018) Crime reporting behaviour: do attitudes toward the police matter? J Interpers Violence 33:2891-2916. https://doi.org/ $10.1177 / 0886260516632356$

Brantingham P, Brantingham P (2011) Crime pattern theory. In Wortley R, Mazerolle L (eds), Environmental criminology and crime analysis (pp 78-93). Routledge

Breetzke GD, Fabris-Rotelli I, Modiba J, Edelstein IS (2021) The proximity of sexual violence to schools: evidence from a township in South Africa. GeoJournal 86:765-776. https://doi.org/10.1007/ s10708-019-10093-3

Canter DV, Gregory A (1994) Identifying the residential location of rapists. J Forensic Sci Soc 34:169-175. https://www.davidcanter. com/wp-content/uploads/2012/04/Residential-Location-of-SerialRapists.pdf

Canter DV, Larkin P (1993) The environmental range of serial rapists. J Environ Psychol 13:63-69. https://doi.org/10.1016/S02724944(05)80215-4

Cohen LE, Felson M (1979) Social change and crime rate trends: a routine activity approach. Am Sociol Rev 44:588-608. https:// doi.org/10.2307/2094589

Cornish D, Clarke R (1986) Situational prevention, displacement of crime and rational choice theory. In Heal K, Laycock G (eds), Situational crime prevention: from theory into practice (pp 1-16). H. M. Stationery Office

Davies A, Dale A (1996) Locating the stranger rapist. Med Sci Law 36:146-156. https://doi.org/10.1177/002580249603600210

Davies K, Alrajeh D, Woodhams J (2018) An investigation into the process of comparative case analysis by analysts working in the Serious Crime Analysis Section in the United Kingdom. A research report prepared for the Serious Crime Analysis Section of the National Crime Agency

Davies K, Woodhams J (2020) An investigation into the process of comparative case analysis conducted by analysts working in the Zeden Analyse Moeurs unit in Belgium. Manuscript in preparation

Department for Transport (2018) Transport statistics Great Britain 2018: Moving Britain ahead. https://assets.publishing.service. gov.uk/government/uploads/system/uploads/attachment_data/ file/787488/tsgb-2018-report-summaries.pdf

Department for Transport (2019) Vehicle licensing statistics: Annual 2018. https://assets.publishing.service.gov.uk/government/ uploads/system/uploads/attachment_data/file/800502/vehiclelicensing-statistics-2018.pdf
Deslauriers-Varin N, Beauregard E (2014) Consistency in crime site selection: an investigation of crime sites used by serial sex offenders across crime series. J Crim Just 42:123-133. https://doi.org/ 10.1016/j.jcrimjus.2013.09.005

Egger SA (1984) A working definition of serial murder and the reduction of linkage blindness. J Police Sci Adm 12:348-357. http:// researchgate.net/publication/245141128_A_Working_Definition_ of_Serial_Murder_and_the_Reduction_of_Linkage_Blindness

Federal Bureau of Investigation (2008) Serial murder: multi-disciplinary perspectives for investigators. US Department of Justice

Grubin D, Kelly P, Brunsdon C (2001) Linking serious sexual assaults through behaviour (Vol. 215). Home Office, Research, Development and Statistics Directorate. https://d1wqtxts $1 x$ zle7.cloudfront.net/2655606/94jdsq7cw1i8wok.pdf? 14250 $85330=\&$ response-content-disposition $=$ inline $\% 3 \mathrm{~B}+$ filename $\%$ 3DLinking_serious_sexual_assaults_through.pdf\&Expires= $1600097899 \&$ Signature $=$ FB kIE m00Ii - RCh Vw SrMbpAJEiskD2UwZu08E1 owR1LgkTiUCTuPNcgdPUh1BnxID3w 7REknrHOzEGeZ2jn6LGn0naMHPjv91Gnf5xPk5aThuBEX tby Y1yGGgACloSawKTEv wIGx V DjdHficQQqNDg2K SW14YN-K ntgDUe4r2qdp905p-XTxymsnJIvuipvNI5VD35 O6gQe24gVTCV-E g9afpUAoQPRd-OB5Pj5rc-jVsWvACTfH i7VeF-awetgBfF1jidwiWTUEnYPM7ip9 fW-wzATf6oeRp 3mq OwM1zfSWQoZksMThLRZPyguWwpJc2gBKx8ngAh6c p9Tbg_\&Key-Pair-Id=APKAJLOHF5GGSLRBV4ZA

Hohl K, Stanko E (2015) Complaints of rape and the criminal justice system: fresh evidence on the attrition problem in England and Wales. Eur J Criminol 12:324-341. https://doi.org/10.1177/ 1477370815571949

Home Office (2019) National ANPR standards for policing and law enforcement. Home Office. https://assets.publishing.service.gov. uk/government/uploads/system/uploads/attachment_data/file/ 806674/NASPLE_-_January_2019_.pdf

Johnson D (2013) The space/time behaviour of dwelling burglars: finding near repeat patterns in serial offender data. Appl Geogr 41:139-146. https://doi.org/10.1016/j.apgeog.2013.04.001

Lammers M (2013) Are arrested and non-arrested serial offenders different? A test of spatial offending patterns using DNA found at crime scenes. J Res Crime Delinq 51:143-167. https://doi.org/10. $1177 / 0022427813504097$

LeBeau JL (1987) The journey to rape: geographic distance and the rapist's method of approaching the victim. J Police Sci Adm 15:129-136

Lovell R, Luminais M, Flannery DJ, Overman L, Huang D, Walker T, Clark DR (2017) Offending patterns for serial sex offenders identified via the DNA testing of previously unsubmitted sexual assault kits. J Crim Just 52:68-78. https://doi.org/10.1016/j.jcrimjus.2017. 08.002

Lundrigan S, Czarnomski S (2006) Spatial characteristics of serial sexual assault in New Zealand. Aust N Z J Criminol 39:218-231. https://doi.org/10.1375/acri.39.2.218

Lundrigan S, Czarnomski S, Wilson M (2010) Spatial and environmental consistency in serial sexual assault. J Investig Psychol Offender Profiling 7:15-30. https://doi.org/10.1002/jip.100

Markson L, Woodhams J, Bond JW (2010) Linking serial residential burglary: comparing the utility of modus operandi behaviours, geographical proximity, and temporal proximity. J Investig Psychol Offender Profiling 7:91-107. https://doi.org/10.1002/jip.120

Ministry of Justice (2020) Criminal Justice Statistics Quarterly: September 2019. Ministry of Justice. https://www.gov.uk/government/ statistics/criminal-justice-system-statistics-quarterly-september-2019

Office for National Statistics (2017) Crime in England and Wales: Year ending June 2017. https://www.ons.gov.uk/releases/ crimeinenglandandwalesyearendingjune 2017

Rebocho MF, Silva P (2014) Target selection in rapists: the role of environmental and contextual factors. Aggress Violent Beh 19:42-49. https://doi.org/10.1016/j.avb.2013.12.003 
Rossmo DK (2000) Geographic profiling. CRC Press

Rossmo DK, Davies A, Patrick M (2004) Exploring the geo-demographic and distance relationships between stranger rapists and their offences. Home Office, Research, Development and Statistics Directorate

Santtila P, Junkkila J, Sandnabba NK (2005) Behavioural linking of stranger rapes. J Investig Psychol Offender Profiling 2:87-103. https://doi.org/10.1002/jip.26

Sarangi S, Youngs D (2006) Spatial patterns of Indian serial burglars with relevance to geographical profiling. J Investig Psychol Offender Profiling 3:105-115. https://doi.org/10.1002/jip.38

Strangeland P (2005) Catching a serial rapist: hits and misses in criminal profiling. Police Pract Res Int J 6:453-469. https://doi.org/10. 1080/15614260500433079

Tonkin M (2014) Testing the theories underpinning crime linkage. In Woodhams J, Bennell C (eds), Crime linkage: theory, research, and practice (pp 107-140). CRC Press. https://doi.org/10.1201/b17591

Tonkin M, Woodhams J, Bull R, Bond JW, Palmer EJ (2011) Linking different types of crime using geographical and temporal proximity. Crim Justice Behav 38:1069-1088. https://doi.org/10.1177/ 0093854811418599

Warren J, Reboussin R, Hazelwood RR, Cummings A, Gibbs N, Trumbetta S (1998) Crime scene and distance correlates of serial rape. J Quant Criminol 14:35-59. https://doi.org/10.1023/A:1023044408529
Waterhouse GF, Reynolds A, Egan V (2016) Myths and legends: the reality of rape offences reported to a UK police force. Eur J Psychol Appl Leg Context 8:1-10

Winter JM, Lemeire J, Meganck S, Geboers J, Rossi G, Mokros A (2013) Comparing the predictive accuracy of case linkage methods in serious sexual assaults. J Investig Psychol Offender Profiling 10:28-56. https://doi.org/10.1002/jip.1372

Woodhams J (2008) Juvenile sex offending: an investigative perspective [Doctoral thesis, University of Leicester]. http://library.college.police. uk/docs/theses/WOODHAMS-juvenile-sex-offending-2008.pdf

Yokota K, Kuraishi H, Wachi T, Otsuka Y, Hirama K, Watanabe K (2017) Practice of offender profiling in Japan. Int J Police Sci Manag 19:187-194. https://doi.org/10.1177/1461355717714001

Youstin TJ, Nobles MR, Ward JT, Cooke CL (2011) Assessing the generalizability of the Near Repeat phenomenon. Crim Justice Behav 38:1042-1063. https://doi.org/10.1177/0093854811417551

Publisher's Note Springer Nature remains neutral with regard to jurisdictional claims in published maps and institutional affiliations. 